\title{
Sodium Removal from Hanford Waste Simulants Using Hydrated Antimony Pentoxide
}

by

L. L. Tovo

Westinghouse Savannah River Company

Savannah River Site

Aiken, South Carolina 29808

J. J. Olson

This paper was prepared in connection with work done under the above contract number with the U.S.

Department of Energy. By acceptance of this paper, the publisher and/or recipient acknowledges the U.S.

Government's right to retain a nonexclusive, royalty-free license in and to any copyright covering this paper, along with the right to reproduce and to authorize others to reproduce all or part of the copyrighted paper. 


\section{DISCLAIMER}

This report was prepared as an account of work sponsored by an agency of the United States Government. Neither the United.States Government nor any agency thereof, nor any of their employees, makes any warranty, express or implied, or assumes any legal liability or responsibility for the accuracy, completeness, or usefulness of any information, apparatus, product, or process disclosed, or represents that its use would not infringe privately owned rights. Reference herein to any specific commercial product, process, or service by trade name, trademark, manufacturer, or otherwise does not necessarily constitute or imply its endorsement, recommendation, or favoring by the United States Government or any agency thereof. The views and opinions of authors expressed herein do not necessarily state or reflect those of the United States Government or any agency thereof.

This report has been reproduced directly from the best available copy.

Available to DOE and DOE contractors from the Office of Scientific and Technical Information, P.O. Box 62, Oak Ridge, TN 37831; prices available from (615) 576-8401.

Available to the public from the National Technical Information Service, U.S. Department of Commerce, 5285 Port Royal Road, Springfield, VA 22161. 


\section{DISCLAIMER}

Portions of this document may be illegible in electronic image products. Images are produced from the best available original document. 


\section{TABLE OF CONTENTS}

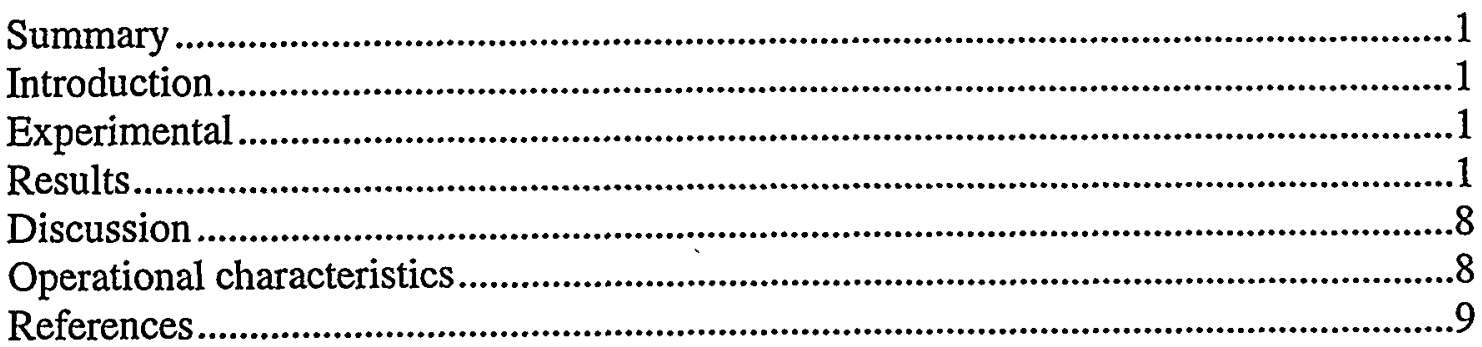


Savannah River Site

WSRC-TR-99-00370

Sodium Removal From Hanford Waste Simulates

Revision 0

Using Hydrated Antimony Pentoxide

September 27, 1999

Page iv

\section{LIST OF FIGURES}

1 Spectral Overlay of the Internal Standard Mass Region for SMD Simulant A................................ 3 and an Instrument Standard

2 Spectral Overlay of the SMD for Simulant B and an Instrument Standard ...................................

3 Overlay of Two Simulant C SMD Samples Treated with HAP..........................................4

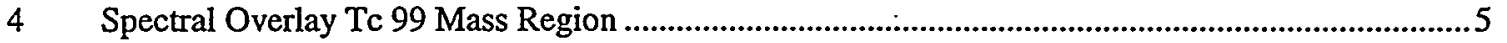

\section{LIST OF TABLES}

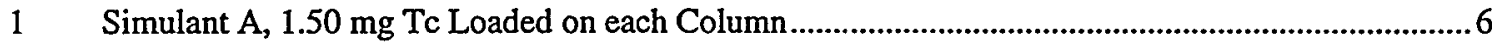

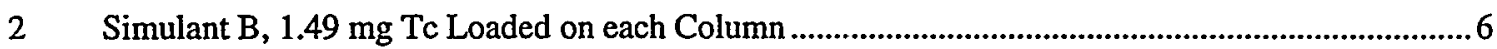

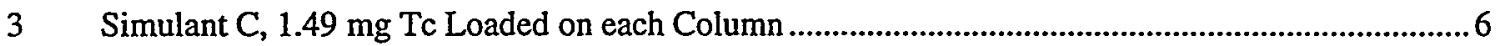

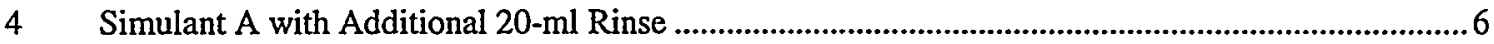

$5 \quad$ Simulant A, Estimated $73.3 \mathrm{Cs}(\mathrm{mg})$ Loaded on Each Column.......................................................7

6 Simulant B, Estimated 48.58 Cs (mg) Loaded on Each Column .....................................................7

7 Simulant C, Estimated $48.58 \mathrm{Cs}(\mathrm{mg})$ Loaded on Each Column ...............................................

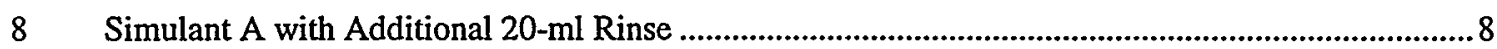




\section{Summary}

Sodium has been removed from each of the three Hanford waste simulants with Hydrated Antimony Pentoxide (HAP) to facilitate technetium measurement by ICP-MS. Technetium was successfully measured in simulants $A$ and $B$ with small dilutions of the simulants (10x). Matrix interference, probably due to organic components, prevented the accurate measurement of $\mathrm{Tc}$ in simulant $\mathrm{C}$.

\section{Introduction}

HAP has been used for the selective removal of sodium from samples prior to radiochemical analysis. ${ }^{1-4}$ The analytical development section of SRTC has successfully used HAP to remove sodium from a simulated sample matrix of a SRS waste tank. ${ }^{5}$ This sample pretreatment method eliminated signal suppression caused by the 5 molar sodium matrix without affecting the concentration of $\mathrm{Pt}, \mathrm{Ru}$, and $\mathrm{Re}$ as measured by Inductively Coupled Plasma-Mass Spectrometry (ICP-MS). With this initial success, we decided to investigate the use of HAP to remove sodium from the three Hanford waste matrices prior to ICP-MS analysis of technetium. The results of this investigation are summarized in this report.

\section{Experimental}

HAP was prepared according to the procedure in reference 6 . Briefly, antimony pentachloride is hydrolyzed, filtered, and dried to produce HAP. The HAP is then ground and sieved for use in columns. This is a three-day process and requires approximately $8 \mathrm{hr}$ of technician time. Commercially available HAP has been used, however it was less effective.

Each of the three Hanford matrices was diluted $10 \mathrm{x}$ and spiked with $150 \mathrm{ppb}$ Tc in $2 \mathrm{M}$ $\mathrm{HNO}_{3}$. These solutions will be referred to as spiked matrix dilution (SMD). Four grams of the HAP was poured into a 10-ml capacity Bio-Rad column and the column was rinsed with $5 \mathrm{ml} 2 \mathrm{M} \cdot \mathrm{HNO}_{3}$. Ten milliliters SMD was loaded onto the column followed by a $10-\mathrm{ml} 2 \mathrm{M} \mathrm{HNO}_{3}$ column rinse. Each portion was collected and analyzed separately. For each SMD, 4 HAP columns were tested to provide data on reproducibility.

\section{Results}

The SMDs from simulant A were analyzed by ICP-ES to confirm sodium removal. ICPES analysis showed sodium concentrations were reduced by a factor of $100 \mathrm{x}$ or greater. Qualitative analysis of ICP-MS data showed that sodium was also significantly reduced in the B and C SMDs. Samples from B and C SMDs have been submitted for sodium analysis by ICP-ES to confirm the sodium removal. 
Indium is added as an internal standard to calibration standards and samples prior to analysis to correct for variations in the instrument performance or matrix effects. Up to a thirty-percent variation in the internal standard response is acceptable and can be corrected based on normalization with the internal standard.

Figures 1-3 are spectra of mass 115 indium from ICP-MS analysis of the SMD for each simulant. Each figure contains spectral overlays of a $2 \% \mathrm{HNO}_{3}$ solution containing only indium (labeled instrument standard), the spike matrix dilution prior to treatment with HAP, and a spiked matrix dilution after treatment with HAP. The indium concentration is the same in all samples, therefore, in the absence of signal suppression or varying instrument response, the indium peak at mass 115 would have the same area in all samples.

In Figure 1, a slightly enhanced $(<15 \%)$ but acceptable internal standard response was observed in the HAP treated SMD. The enhanced response is most likely due to instrument performance variation. The overlay shows extreme signal suppression in the .. untreated SMD. This suppression would prevent accurate quantification of any sample analytes.

In Figure 2, significant signal suppression is not observed in the untreated SMD and therefore quantification is possible using internal standard.

Figure 3 displays an overlay of two simulant C SMD samples treated with HAP. During the ICP-MS analysis sequence, a significant decrease in instrument response was observed. The cause of this decrease is being investigated. 
Figure 1. Spectral overlay of the internal standard mass region for SMD simulant A and an instrument standard.

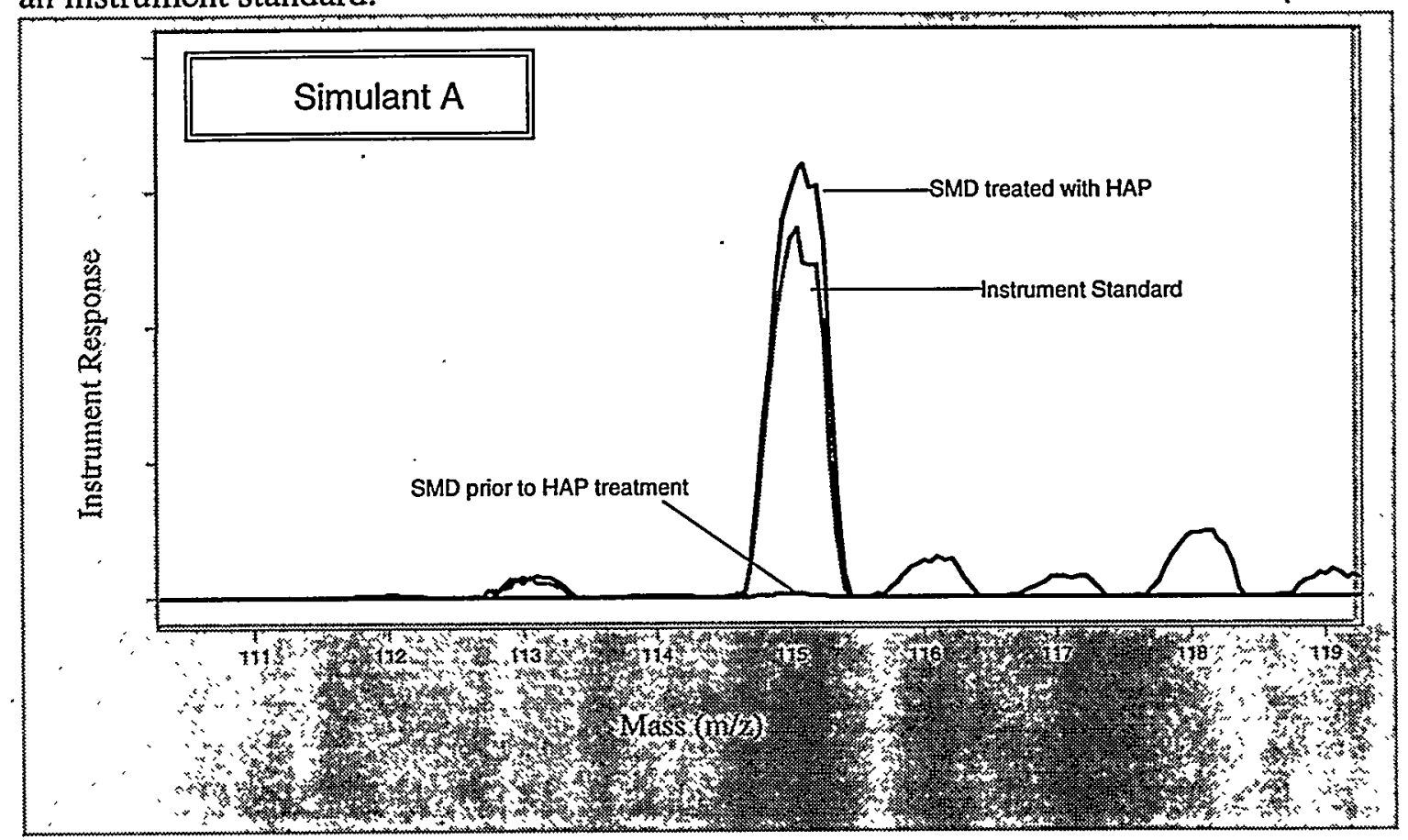

Figure 2. Spectral overlay of the SMD for simulant B and an instrument standard.

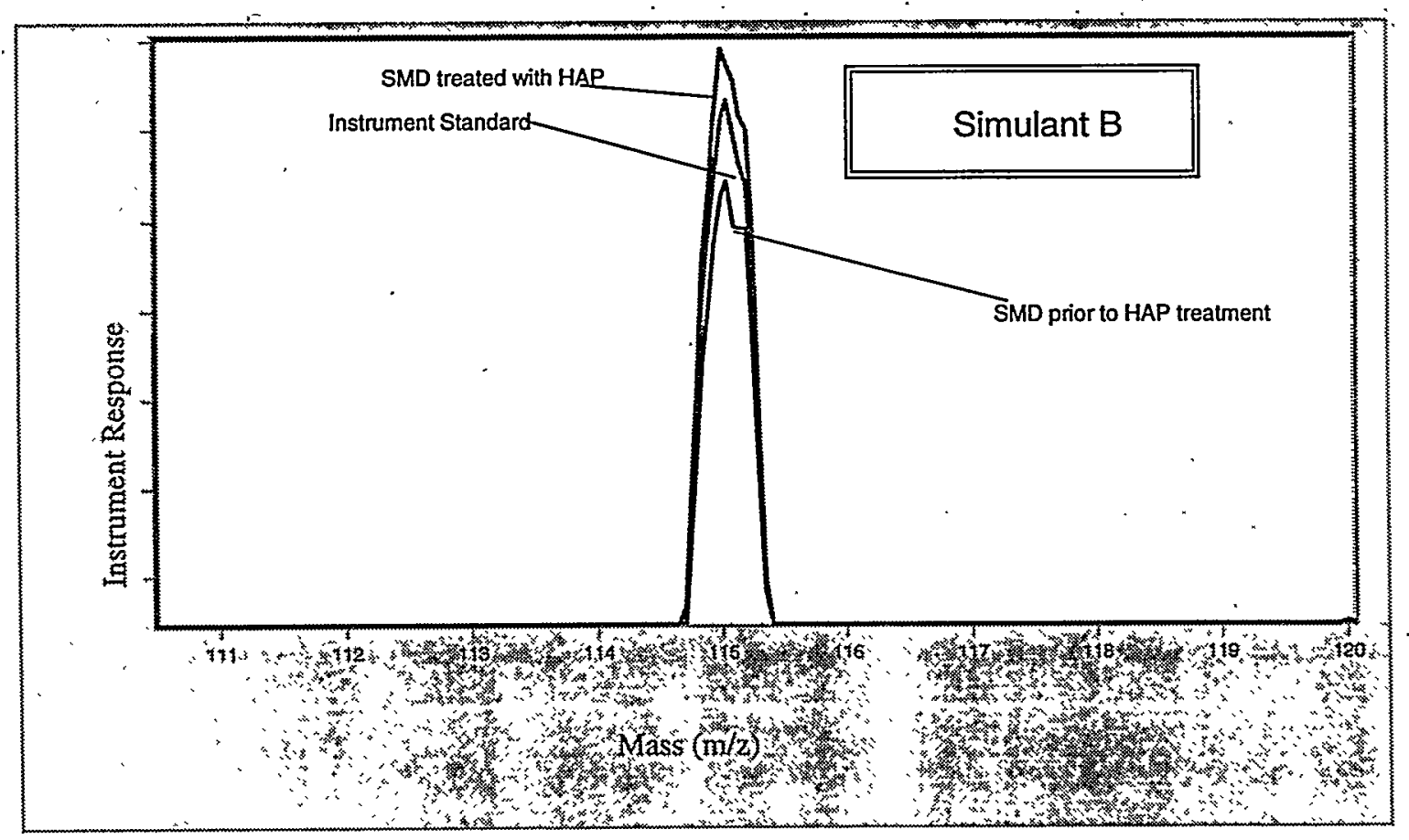


Savannah River Site

WSRC-TR-99-00370

Sodium Removal From Hanford Waste Simulates

Revision 0

Using Hydrated Antimony Pentoxide

September 27, 1999

Page 4

Figure 3. Overlay of two simulant C SMD samples treated with HAP.

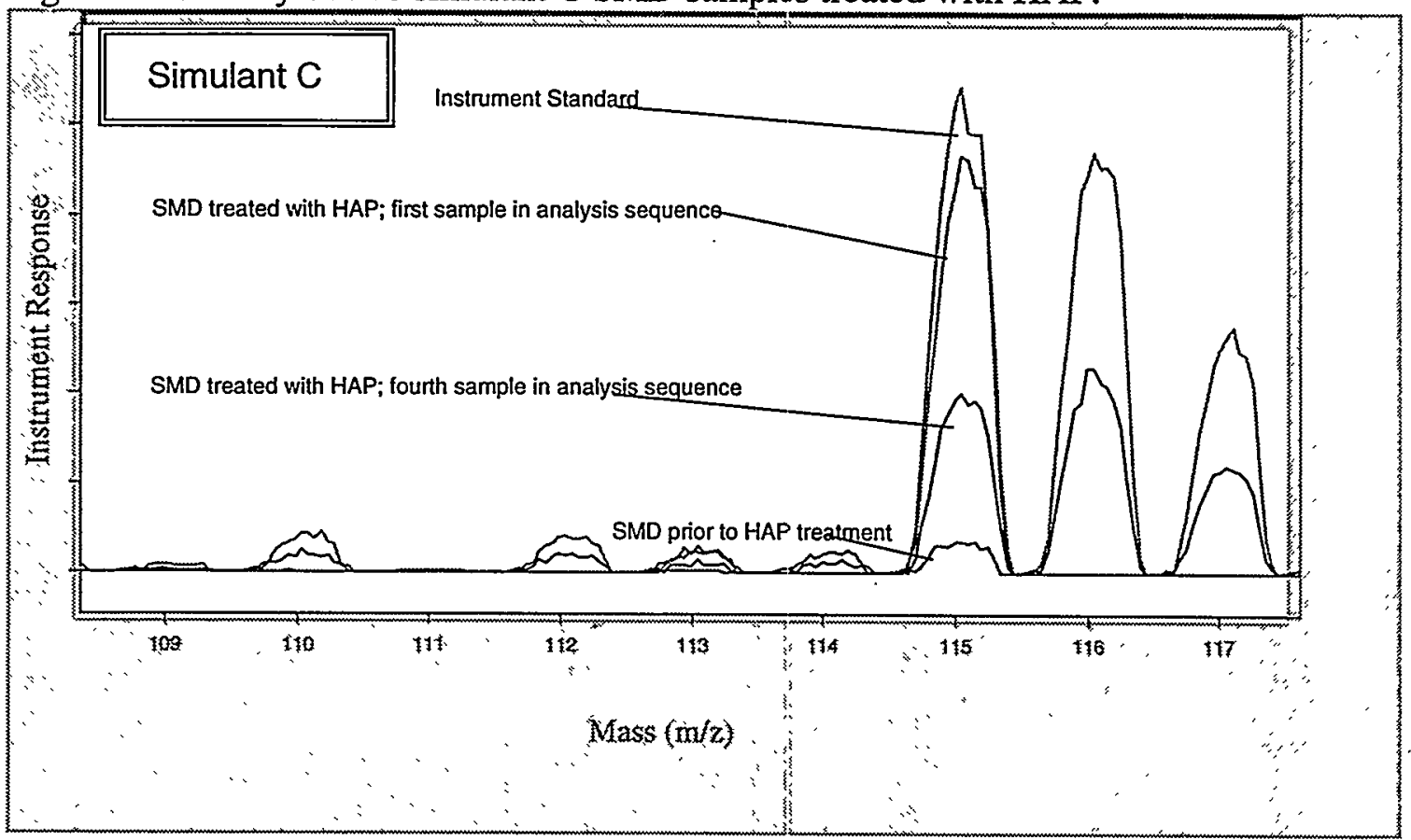


In Figure 4, spectra of mass 99, Tc, is shown. The Tc concentration in these two samples is the same, however due to signal suppression the peak area for the untreated sample is much smaller than the HAP treated sample. Note the similar response pattern for the Tc and In (see Figure 1) in these two samples.

Figure 4. Spectral overlay Tc 99 mass region.

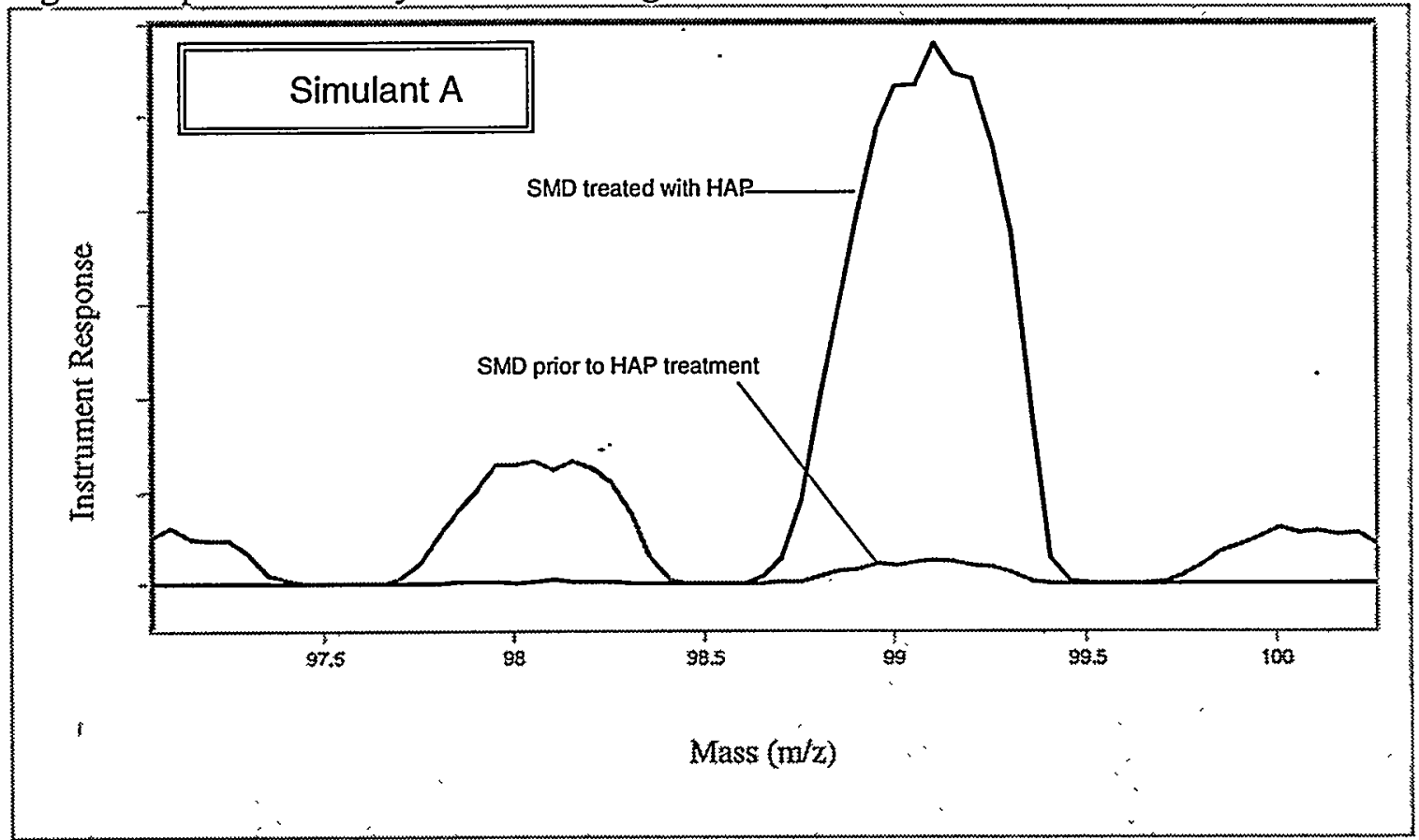


Tables 1-3 summarize the Tc recovery from the three Hanford simulants treated with $\mathrm{HAP}$. The mass of $\mathrm{Tc}$ is calculated by converting the concentration of $\mathrm{Tc}$ measured by ICP-MS analysis to mass based on the sample volume. For example, the spiked matrix solution for simulant A has a Tc concentration of $150 \mathrm{ppb}$. Ten milliliters of this solution was loaded onto the columns, therefore a total of 1.5 milligrams $\mathrm{Tc}$ was loaded onto each column. To calculate the total mass recovered, the mass in the eluted SMD and the column rinse were added.

Table 1 Simulant A, $1.50 \mathrm{mg}$ Tc loaded on each column

\begin{tabular}{|c|c|c|}
\hline Column \# & $\begin{array}{c}\text { Tc (mg) } \\
\text { recovered }\end{array}$ & $\begin{array}{c}\text { Tc (\%) } \\
\text { recovered }\end{array}$ \\
\hline 1 & 0.96 & 64.1 \\
\hline 2 & 1.39 & 92.6 \\
\hline 3 & 1.43 & 95.0 \\
\hline 4 & 1.29 & 85.7 \\
\hline
\end{tabular}

Table 2 Simulant B, $1.49 \mathrm{mg}$ Tc loaded on each column

\begin{tabular}{|c|c|c|}
\hline Column \# & $\begin{array}{c}\text { Tc (mg) } \\
\text { recovered }\end{array}$ & $\begin{array}{c}\text { Tc (\%) } \\
\text { recovered }\end{array}$ \\
\hline 1 & 1.33 & 89.3 \\
\hline 2 & 1.31 & 87.7 \\
\hline 3 & 1.30 & 87.1 \\
\hline 4 & 1.30 & 87.1 \\
\hline
\end{tabular}

Table 3 Simulant C, $1.49 \mathrm{mg}$ Tc loaded on each column

\begin{tabular}{|c|c|c|}
\hline Column \# & $\begin{array}{c}\text { Tc (mg) } \\
\text { recovered }\end{array}$ & $\begin{array}{c}\text { Tc (\%) } \\
\text { recovered }\end{array}$ \\
\hline 1 & 1.47 & 98.7 \\
\hline 2 & 1.57 & 105.4 \\
\hline 3 & 1.78 & 119.7 \\
\hline 4 & 1.85 & 124.3 \\
\hline
\end{tabular}

To determine if a 10-ml rinse was a sufficient elution volume, an additional 20-ml rinse was added to each of the columns for simulant A. Results with the additional mass recovered from the 20 -ml rinse added to the original mass recovered are reported in Table 4. Based on this data, we decided to proceed using one $10-\mathrm{ml}$ rinse.

Table 4 Simulant A with additional 20-ml rinse

\begin{tabular}{|c|c|c|c|}
\hline Column \# & $\begin{array}{c}\text { Tc (mg) } \\
\text { recovered }\end{array}$ & $\begin{array}{c}\text { Tc (\%) } \\
\text { recovered }\end{array}$ & $\begin{array}{c}\text { \% Increase in } \\
\text { recovery from } \\
\text { 10-ml rinse }\end{array}$ \\
\hline 1 & 0.99 & 65.9 & 1.8 \\
\hline 2 & 1.40 & 93.6 & 1.0 \\
\hline 3 & 1.44 & 96.1 & 1.0 \\
\hline 4 & 1.30 & 86.7 & 1.0 \\
\hline
\end{tabular}


Cs is present in all three Hanford waste simulants. Although not part of our original work scope, Cs retention by the HAP columns was also quantified. For some applications, it may be useful to remove the $\mathrm{Cs}$ along with the $\mathrm{Na}$. Cesium milligrams loaded on column, milligrams recovered, and percent recovered were calculated in the same manner as the Tc data and is summarized in Tables 5-7.

Table 5. Simulant A, Estimated 73.3 Cs (mg) loaded on each column

\begin{tabular}{|c|c|c|}
\hline Column \# & $\begin{array}{c}\text { Cs (mg) } \\
\text { recovered }\end{array}$ & $\begin{array}{c}\text { Cs (\%) } \\
\text { recovered }\end{array}$ \\
\hline 1 & 4.71 & 6.4 \\
\hline 2 & 6.36 & 8.7 \\
\hline 3 & 0.04 & $<0.1$ \\
\hline 4 & 0.52 & 0.7 \\
\hline
\end{tabular}

Table 6. Simulant B, Estimated $48.58 \mathrm{Cs}$ (mg) loaded on each column

\begin{tabular}{|c|c|c|}
\hline Column \# & $\begin{array}{c}\text { Cs (mg) } \\
\text { recovered }\end{array}$ & $\begin{array}{c}\text { Cs (\%) } \\
\text { recovered }\end{array}$ \\
\hline 1 & 3.04 & 6.3 \\
\hline 2 & 5.82 & 12.0 \\
\hline 3 & 2.47 & 5.1 \\
\hline 4 & 5.86 & 12.1 \\
\hline
\end{tabular}

Table 7. Simulant C, Estimated $48.58 \mathrm{Cs}$ (mg) loaded on each column

\begin{tabular}{|c|c|c|}
\hline Column \# & $\begin{array}{c}\text { Cs (mg) } \\
\text { recovered }\end{array}$ & $\begin{array}{c}\text { Cs (\%) } \\
\text { recovered }\end{array}$ \\
\hline 1 & 11.58 & 51.3 \\
\hline 2 & 15.70 & 69.5 \\
\hline 3 & 14.22 & 63.0 \\
\hline 4 & 14.91 & 66.0 \\
\hline
\end{tabular}


Cs recoveries were also calculated from the additional 20-ml rinse applied to the simulant A columns. A significant increase in Cs recoveries was observed with the additional rinse volume, results are summarized in Table 8.

Table 8. Simulant $A$ with additional $20-\mathrm{ml}$ rinse

\begin{tabular}{|c|c|c|c|}
\hline Column \# & $\begin{array}{c}\text { Cs (mg) } \\
\text { recovered }\end{array}$ & $\begin{array}{c}\text { Cs (\%) } \\
\text { recovered }\end{array}$ & $\begin{array}{c}\text { \% Increase } \\
\text { in recovery } \\
\text { from 10-ml } \\
\text { rinse }\end{array}$ \\
\hline 1 & 17.31 & 23.6 & 17.2 \\
\hline 2 & 19.33 & 26.4 & 17.7 \\
\hline 3 & 15.09 & 20.6 & 20.6 \\
\hline 4 & 15.47 & 21.1 & 20.4 \\
\hline
\end{tabular}

\section{Discussion}

HAP treatment of simulant A effectively removed sodium, as measured by ICP-ES, and allowed measurement of Tc by ICP-MS. Without HAP treatment of the simulant A SMD, the sample would have required a large dilution for ICP-MS analysis. The dilution required would have diluted the Tc near to or below the instrument detection limits. Based on the consistent recoveries from Table 1, columns 2-4, the low recovery for column 1 is thought to be due to an error in loading the column with the SMD.

No significant signal suppression was observed in analysis of the SMD for simulant B. Qualitative analysis of the sodium mass region from ICP-MS spectra indicates successful sodium removal. Although signal suppression was not observed in the analysis of simulant B SMD, removal of excess sodium is helpful in preventing instrument downtime caused by the build up of sodium on the instrument hardware.

HAP treatment of simulant C SMD did not eliminate signal suppression. As the analysis sequence proceeded, the signal suppression increased (Fig. 3). We suspect the presence of organics in this simulant causes the observed signal suppression. Since the Tc and Cs concentrations calculated from the ICP-MS data are corrected for internal standard (indium) response, this increasing signal suppression may have resulted in erroneous concentration calculations for recovery of Tc and Cs. Note the increasing recoveries for both Tc and Cs in Tables 3 and 7 .

\section{Operational Characteristics}

Hydrated antimony pentoxide is a useful tool to reduce signal suppression caused by high sodium concentrations in sample matrices. Scaling up HAP production would require analysis of potential safety hazards associated with the exothermic hydrolysis step. The time spent grinding HAP may be reduced by the use of an electric grinder. We will evaluate the use of an electric grinder next week. With the current column procedure, 
HAP could be used as an at-line process for sample preparation prior to ICP-MS or ICPES analysis. However, the elution time for the sample and one rinse is approximately 3 hr. When using the HAP to treat SRS waste tank matrices, column elution time was much shorter. We are trying to determine the cause for the long sample elution time with the Hanford matrices. It may be possible to greatly reduce the process time by using HAP in a batch versus column mode.

\section{References}

1. Giradi F, Sabbioni E (1968) J. Radioanal. Chem. 1:16-170.

2. Girarid F, Pietra R, Sabbioni E (1970) J. Radioanal. Chem. 5: 141-171.

3. Gills TE, Marlow WF, Thompson BA. (1970) 42: 1831-1833.

4. Nyarku SK. (1984) Analytical Letters 17:2213-2220.

5. Tovo LL, Boyce WT (1998) FACCS conference proceedings.

6. Los Alamos Collected Radiochemical Procedures, $4^{\text {th }}$ Edition, LA1721. 